\title{
Hypertension treatment in the elderly: a SPRINT to the finish
}
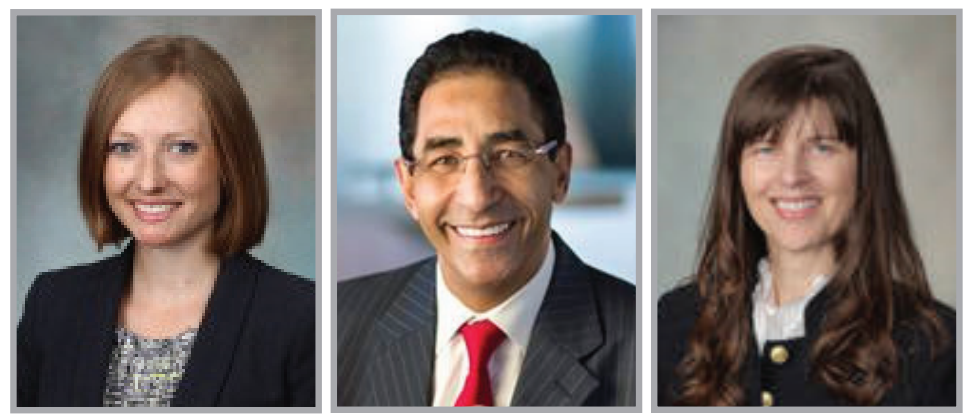

Christine Parsons ${ }^{1}$, Farouk Mookadam ${ }^{*, 2} \&$ Martina Mookadam ${ }^{3}$

First draft submitted: 30 November 2016; Accepted for publication: 9 January 2017; Published online: 10 February 2017

Hypertension (HTN) is a major cardiovascular $(\mathrm{CV})$ and cerebrovascular risk factor widely prevalent in the elderly $[1,2]$. Treatment of HTN in the elderly has been shown to reduce major adverse $\mathrm{CV}$ events including stroke [3,4]. However, the optimal blood pressure (BP) target in this population is unclear. The Eighth Joint National Committee guidelines recommend treatment of HTN in the general population $\geq 60$ years to a goal systolic $\mathrm{BP}(\mathrm{SBP})<150 \mathrm{mmHg}$ [5]. Expert opinion noted that treatment does not need to be adjusted if an SBP $<150 \mathrm{mmHg}$ is achieved and well tolerated.

European guidelines recommend even higher cutoffs for initiating antihypertensive therapy (SBP $>160 \mathrm{mmHg}$ ) in those $\geq 80$ years [6]. However, recent analysis of the SPRINT trial in adults $\geq 75$ years found that intensive compared with standard SBP targets resulted in lower composite CV disease (CVD) outcomes and all-cause mortality [7]. The SPRINT results have sparked debate regarding optimal treatment targets given conflicting findings with previous trials and existing guidelines.

SPRINT was a randomized, open-label trial of community-dwelling older adults $(n=9361$; mean age: 68 years; median follow-up: 3.26 years) that evaluated whether lowering SBP to a target $<120$ versus $<140 \mathrm{mmHg}$ reduced major $\mathrm{CV}$ events [8]. Inclusion criteria included age $\geq 50$ years, SBP $130-180 \mathrm{mmHg}$ (mean baseline BP 140/78 $\mathrm{mmHg}$ ) and increased $\mathrm{CV}$ risk (CVD, chronic kidney disease, Framingham 10-year CVD risk score $\geq 15 \%$ or age $\geq 75$ years). Exclusion criteria included standing SBP $<110 \mathrm{mmHg}$, history of stroke, diabetes mellitus, proteinuria, symptomatic heart failure or ejection fraction $<35 \%$, unintentional weight loss $>10 \%$, anticipated survival $<3$ years or nursing home residence.

The primary composite outcome of major CVD events (myocardial infarction, acute coronary syndrome, stroke, acute heart failure and CV death) occurred in

\section{KEYWORDS}

-antihypertensive $\bullet$ blood pressure target $\bullet$ cardiovascular risk • cerebrovascular risk • elderly - hypertension • therapy • SPRINT 


\section{"SPRINT showed that in \\ hypertensive adults}

without diabetes, lowering

systolic blood pressure to a

goal $<120 \mathrm{mmHg}$

compared with

$<140 \mathrm{mmHg}$ resulted in

significantly lower rates of

fatal and nonfatal

cardiovascular disease

events and death from any cause."
243 individuals in the intense treatment group versus 319 in the less intense group (hazard ratio [HR]: 0.75; 95\% CI: 0.64-0.89; p < 0.001; number needed to treat $[N N T]=61)$. There was significantly less all-cause mortality in the intensive versus standard group (HR: 0.73; 95\% CI: 0.60 $0.90 ; p=0.003)$. Baseline SBP at different levels $(\leq 132,132-145$ and $\geq 145 \mathrm{mmHg}$ ) was evaluated prospectively and all groups favored intensive treatment. Those with a baseline SBP $\leq 132$ mmHg had an HR: 0.70 (95\% CI: 0.51-0.95) comparing intensive versus standard therapy on CVD events.

Another predefined subgroup of interest included those $\geq 75$ years of age $(27.4 \%)$ [7] There was a significantly lower rate of CVD events in the intensive compared with the standard treatment group (102 vs 148 events, HR: $0.66 ; 95 \%$ CI: 0.51-0.85; NNT = 27). All-cause mortality was also significantly lower (HR: 0.67; 95\% CI: 0.49-0.91; NNT = 41). The mean SBPs through follow-up were 123.4 and $134.8 \mathrm{mmHg}$ in the intensive and standard groups, respectively.

There was no significant difference in serious adverse events between groups in the overall and elderly subgroup SPRINT analyses. However, there were a large percentage of serious adverse events in both groups, particularly in those $\geq 75$ years ( $48.4 \%$ in the intensive vs $48.3 \%$ in the standard group). Injurious falls and orthostatic hypotension did not occur significantly more frequently in the intensive group.

The SPRINT results may not be generalizable as study exclusions may have selected for a 'healthier' cohort than the general community. For instance, nursing home and assisted living patients and those with more severe HTN or heart failure, or a history of diabetes or stroke were excluded. Other limitations include that a substantial number of patients had SBPs above target and there was a low rate of aspirin and statin use.

A recent systematic review and meta-analysis of randomized controlled trials $(\mathrm{n}=44989$; 19 trials, mean follow-up: 3.8 years) found that intensive versus less intensive HTN treatment achieved a $14 \%$ relative risk reduction for major CV events (95\% CI: 4-22); however, no significant effect was seen on CV or all-cause mortality [9]. Additional BP lowering had a clear benefit even in patients with SBPs $<140 \mathrm{mmHg}$.

A key concern in targeting lower BPs is associated adverse effects. In their meta-analysis of trials evaluating intensive versus less intensive hypertensive treatment, Xie et al. noted that adverse effects were incompletely collected. Serious adverse events were only reported by six trials and were not significantly different between intensive and standard treatment groups (relative risk: 1.35; 95\% CI: 0.93-1.97). Severe hypotension was more frequent in the more intensive treatment group, but the absolute excess was small. Data regarding falls and fractures were scarce.

A number of large trials prior to SPRINT have shown reduced CVD events and mortality with HTN treatment in the elderly, although trials with similar lower BP targets have been underpowered. The SHEP trial $(\mathrm{n}=4736$; mean age: 71.6 years; mean follow-up: 4.5 years) showed a significant reduction in CV events and all-cause mortality with antihypertensive compared with placebo treatment of isolated systolic HTN (mean SBP: 143 vs $155 \mathrm{mmHg}$, respectively) [10]. The HYVET ( $\mathrm{n}=3845$; mean age: 83.6 years; mean follow-up: 1.8 years) randomized hypertensive adults $\geq 80$ years to placebo or treatment with indapamide with or without perindopril [11]. Treatment achieved a $15 \mathrm{mmHg}$ lower SBP (mean, $143 \mathrm{mmHg}$ ) and was associated with a significant reduction in stroke, $\mathrm{CV}$ and all-cause mortality. Fewer serious adverse events were reported in the active-treatment group ( $\mathrm{p}=0.001)$. Thus, the SHEP trial and HYVET indicate that reducing SBP to around $140 \mathrm{mmHg}$ has substantial benefit without major harm in older adults.

Significant CV benefit was not seen for more intensive HTN treatment in the VALISH trial, but the BP separation was small $(5.4 \mathrm{mmHg})$ [12]. The JATOS had a similar incidence of the primary $\mathrm{CV}$ and renal end point in both treatment groups (<140 vs $140-160 \mathrm{mmHg}$ ) [13]. The ACCORD trial in patients with diabetes did not demonstrate significant $\mathrm{CV}$ benefit for treatment to SBP $<120 \mathrm{mmHg}$ compared with $<140 \mathrm{mmHg}$ [14]. Still, the rate of stroke was significantly lower in the $<120 \mathrm{mmHg}$ group. It is possible that the intervention effect may be modified by baseline variables, such as diabetes mellitus given that a significant treatment effect was seen in SPRINT, which excluded those with diabetes. The SPS3 trial indicated that an SBP target $<130$ versus $130-149 \mathrm{mmHg}(\mathrm{n}=3020$; mean age: 63 years; mean SBP: 127 vs $138 \mathrm{mmHg}$ ) reduced stroke and myocardial infarction or vascular death, although findings were not significant [15]. 
The reasoning that lower $\mathrm{BP}$ targets than those recommended by current standards will result in fewer CV events is based on the relationship seen with prospective observational data. A large meta-analysis of individuals without baseline CVD ( $\mathrm{n}=958074)$ found that lower BP (down to $115 / 75 \mathrm{mmHg}$ ) across all age groups was associated with decreased CV outcomes [2]. However, this theory presumes that the same relationship would be seen when similar BPs are induced in hypertensive patients and in those with CVD.

The ideal BP target is not known and whether this would vary by the presence of certain comorbidities including frailty. Studies are conflicting regarding an interaction between treatment effect and frailty $[16,17]$. Some studies have suggested a J-curve association between BP and $\mathrm{CV}$ outcomes, implying diminishing benefit and raising concern that excess BP lowering could potentially increase risk [18].

The SPRINT $\geq 75$ years subgroup findings argue that lower targets should be sought in the elderly. However, negative side effects, particularly hypotension and falls, likely make physicians weary to apply this to their clinical practice. We feel that it is reasonable to conduct an individualized risk-benefit assessment to determine whether lower targets should be pursued. Active patient-physician communication and scheduled follow-ups with BP and side effect logs may be employed. Adopting an individualized approach, for instance incorporating life expectancy, frailty, and other patient factors and patient or family preferences, is consistent with recommendations for preventative care in the elderly [19].

SPRINT showed that in hypertensive adults without diabetes, lowering SBP to a goal $<120 \mathrm{mmHg}$ compared with $<140 \mathrm{mmHg}$ resulted in significantly lower rates of fatal and nonfatal CVD events and death from any cause. This finding was consistent across evaluated subgroups, including in patients $\geq 75$ years. Good evidence supports lower SBP targets than those currently recommended for most hypertensive elderly patients. An individualized approach weighing side effects and treatment effort against the degree of benefit should be employed. Further prospective trials in representative populations of community dwelling older adults, which examine common baseline comorbidities, frailty and specific lower BP targets are needed.

\section{Financial \& competing interests disclosure}

The authors have no relevant affliations or financial involvement with any organization or entity with a financial interest in or financial conflict with the subject matter or materials discussed in the manuscript. This includes employment, consultancies, honoraria, stock ownership or options, expert testimony, grants or patents received or pending, or royalties.

No writing assistance was utilized in the production of this manuscript.

\section{References}

1 Rapsomaniki E, Timmis A, George J et al. Blood pressure and incidence of twelve cardiovascular diseases: lifetime risks, healthy life-years lost, and age-specific associations in 1.25 million people. Lancet 383(9932), 1899-1911 (2014).

2 Lewington S, Clarke R, Qizilbash N, Peto R, Collins R, Prospective Studies C. Age-specific relevance of usual blood pressure to vascular mortality: a meta-analysis of individual data for one million adults in 61 prospective studies. Lancet 360(9349), 1903-1913 (2002).

3 Parsons C, Murad MH, Andersen S, Mookadam F, Labonte $\mathrm{H}$. The effect of antihypertensive treatment on the incidence of stroke and cognitive decline in the elderly: a meta-analysis. Future Cardiol. 12(2), 237-248 (2016)

4 Musini VM, Tejani AM, Bassett K, Wright JM. Pharmacotherapy for hypertension in the elderly. Cochrane Database Syst. Rev. (4), CD000028 (2009).

5 James PA, Oparil S, Carter BL et al. 2014 evidence-based guideline for the management of high blood pressure in adults: report from the panel members appointed to the Eighth Joint National Committee (JNC 8). JAMA 311(5), 507-520 (2014).

6 Mancia G, Fagard R, Narkiewicz K et al. 2013 ESH/ESC guidelines for the management of arterial hypertension: the Task Force for the Management of Arterial Hypertension of the European Society of Hypertension (ESH) and of the European Society of Cardiology (ESC). Eur. Heart J. 34(28), 2159-2219 (2013).

7 Williamson JD, Supiano MA, Applegate WB et al. Intensive vs standard blood pressure control and cardiovascular disease outcomes in adults aged $\geq 75$ years: a randomized clinical trial. JAMA 315(24), 2673-2682 (2016).
8 Group SR, Wright JT Jr, Williamson JD et al. A randomized trial of intensive versus standard blood-pressure control. N. Engl. J. Med. 373(22), 2103-2116 (2015).

9 Xie X, Atkins E, Lv J et al. Effects of intensive blood pressure lowering on cardiovascular and renal outcomes: updated systematic review and meta-analysis. Lancet 387(10017), 435-443 (2016).

10 Prevention of stroke by antihypertensive drug treatment in older persons with isolated systolic hypertension. Final results of the Systolic Hypertension in the Elderly Program (SHEP). SHEP Cooperative Research Group. JAMA 265(24), 3255-3264 (1991).

11 Beckett NS, Peters R, Fletcher AE et al. Treatment of hypertension in patients 80 years of age or older. N. Engl. J. Med. 358(18), 1887-1898 (2008).

12 Ogihara T, Saruta T, Rakugi H et al. Target blood pressure for treatment of isolated systolic hypertension in the elderly: valsartan 
EDITORIAL Parsons, Mookadam \& Mookadam

in elderly isolated systolic hypertension study. Hypertension 56(2), 196-202 (2010).

13 Group JS. Principal results of the Japanese trial to assess optimal systolic blood pressure in elderly hypertensive patients (JATOS). Hypertens. Res. 31(12), 2115-2127 (2008).

14 Group AS, Cushman WC, Evans GW et al. Effects of intensive blood-pressure control in Type 2 diabetes mellitus. N. Engl. J. Med. 362(17), 1575-1585 (2010).

15 Group SPSS, Benavente OR, Coffey CS et al. Blood-pressure targets in patients with recent lacunar stroke: the SPS3 randomised trial. Lancet 382(9891), 507-515 (2013).

16 Warwick J, Falaschetti E, Rockwood K et al. No evidence that frailty modifies the positive impact of antihypertensive treatment in very elderly people: an investigation of the impact of frailty upon treatment effect in the HYpertension in the Very Elderly Trial (HYVET) study, a double-blind, placebocontrolled study of antihypertensives in people with hypertension aged 80 and over. BMC Med. 13, 78 (2015)
17 Charlesworth CJ, Peralta CA, Odden MC. Functional status and antihypertensive therapy in older adults: a new perspective on old data. Am. J. Hypertens. 29(6), 690-695 (2016).

18 Chalmers J. Is a blood pressure target of $<130 / 80 \mathrm{mmHg}$ still appropriate for high-risk patients? Circulation 124(16), 1700-1702 (2011).

19 Tazkarji B, Lam R, Lee S, Meiyappan S. Approach to preventive care in the elderly. Can. Fam. Physician 62(9), 717-721 (2016). 